\title{
Enhancement of Behavioral and Electroencephalographic Indices of Waking following Stimulation of Noradrenergic $\beta$-Receptors within the Medial Septal Region of the Basal Forebrain
}

\author{
Craig W. Berridge ${ }^{1}$ and Stephen L. Foote ${ }^{2}$ \\ ${ }^{1}$ Psychology Department, University of Wisconsin, Madison, Wisconsin 53706-1611, and ${ }^{2} P$ sychiatry Department, \\ University of California, San Diego, La Jolla, California 92093
}

Previous studies in halothane-anesthetized rat documented potent electroencephalographic (EEG) modulatory actions of the locus coeruleus (LC) noradrenergic system, with LC neuronal activity causally related to the maintenance of EEG activity patterns associated with enhanced arousal/alertness. Recent studies, also in halothane-anesthetized rat, demonstrated that the region of the basal forebrain encompassing the medial septum/vertical limb of the diagonal band of Broca (MS) is a site at which noradrenergic efferents act to influence EEG state via actions at $\beta$-receptors.

These and other observations are consistent with the hypothesis that the LC noradrenergic system participates in the modulation of behavioral state. However, the degree to which this system modulates EEG state in the absence of anesthesia and to what extent such actions are accompanied by behavioral modulatory actions remain to be determined. The current studies examined whether small infusions of isoproterenol (ISO), a $\beta$-adrenergic agonist, into MS alter behavioral, EEG, and electromyographic (EMG) measures of sleep and waking in the resting, undisturbed rat.

These infusions resulted in a significant increase in time spent awake, defined by both behavioral and EEG/EMG measures, and in the nearly complete suppression of REM sleep. EEG/EMG responses either coincided with or preceded behavioral responses by 10-320 sec. The pattern of behavioral responses observed following MS-ISO infusions was qualitatively similar to that associated with normal waking. Infusions of vehicle into MS or ISO into sites adjacent to MS did not elicit consistent alterations in behavioral state. These results suggest that the LC noradrenergic system exerts potent behavioral and EEG-activating effects via actions of norepinephrine at $\beta$-receptors located within MS.

Key words: norepinephrine; medial septum; arousal; EEG; $\beta$-receptors; sleep; locus coeruleus
The locus-coeruleus (LC) is a small brainstem nucleus that through an extensive efferent projection system is the major source of brain norepinephrine (NE). A number of observations suggest a functional relationship between LC neuronal activity and behavioral state. For example, tonic LC discharge activity is state-dependent, with higher rates observed in waking than in sleep, and these changes in LC-discharge activity precede changes in EEG and behavioral measures of state (Hobson et al., 1975; Foote et al., 1980; Aston-Jones and Bloom, 1981a; Aston-Jones et al., 1994; Foote and Aston-Jones, 1995). Within waking, LC neurons respond phasically to sensory stimuli of sufficient potency or saliency to elicit an orienting response (Foote et al., 1980; Aston-Jones and Bloom, 1981b). Despite extensive study, the behavioral and physiological functions of alterations in activity of the LC noradrenergic system remain enigmatic.

Forebrain EEG displays state-dependent activity patterns (Timo-Iaria et al., 1970; Vanderwolf and Robinson, 1981). In previous studies in halothane-anesthetized rat, we tested the hypothesis that experimentally induced changes in tonic LC neuronal discharge rates would produce corresponding changes in fore-

Received May 7, 1996; revised July 18, 1996; accepted Aug. 6, 1996.

This work was supported by a grant from the University of Wisconsin Graduate School (C.W.B.), Public Health Service Grant MH40008 (S.L.F.), and Air Force Office of Scientific Research Grant F49620 (S.L.F.). We gratefully acknowledge the expert technical assistance of Amy Klemm, Elizabeth Mitton, Ginger Stickney, and Kelly Wifler.

Correspondence should be addressed to Dr. Craig W. Berridge, Psychology Department, University of Wisconsin, 1202 West Johnson, Madison, WI 53706-1611.

Copyright (C) 1996 Society for Neuroscience $0270-6474 / 96 / 166999-11 \$ 05.00 / 0$ brain EEG state. Documented manipulations of LC neuronal activity were shown to be causally related to the initiation and maintenance of EEG activity patterns associated with enhanced alertness/arousal (Berridge and Foote, 1991; Berridge et al., 1993; Page et al., 1993).

Subsequent studies under similar experimental conditions identified the region of the basal forebrain containing the medial septum/vertical limb of the diagonal band of Broca (MS) as a critical site at which noradrenergic projections, presumably from LC (Segal, 1976; Zaborsky et al., 1991), act to influence EEG state via actions at $\beta$-noradrenergic receptors (Berridge et al., 1996). For example, unilateral infusions of the $\beta$-agonist isoproterenol (ISO) $(150 \mathrm{nl})$ into MS elicit bilateral activation of forebrain EEG. Conversely, bilateral infusions of the $\beta$-antagonist timolol decrease EEG indices of arousal, indicating a tonic, EEGactivating action of endogenous NE via actions at $\beta$-receptors within MS. Further, in preliminary studies, bilateral infusions of timolol into MS blocked EEG activation induced by enhancement of LC discharge rates (C. Berridge and S. Foote, unpublished observations). Combined, these results indicate that LC efferents exert potent EEG modulatory actions in the halothaneanesthetized rat through actions of NE at $\beta$-receptors located within MS.

The anesthetized preparation facilitates stable EEG and LC electrophysiological recordings to assess infusion-induced LC and EEG responses and permits the performance of mapping studies using a within-subjects design. Therefore, this preparation enhanced the confidence with which results could be specifically 
ascribed to actions of the LC noradrenergic system and facilitated identification of discrete anatomical sites (e.g., MS) in which NE acts to alter EEG activity. However, to obtain a clearer understanding of the behavioral functions of the LC noradrenergic system, it is essential to determine the degree to which manipulations of this system, or selected LC terminal fields, modulates forebrain EEG in the unanesthetized animal and whether changes in EEG state are associated with concomitant changes in behavioral state. The present studies examine the behavioral, EEG, and electromyographic (EMG) effects of small infusions of the noradrenergic $\beta$-agonist ISO made into or immediately adjacent to MS in the undisturbed, resting rat.

A portion of these results has been presented previously in abstract form (Berridge and Foote, 1993).

\section{MATERIALS AND METHODS}

Animals and surgery. Male Sprague Dawley rats (Charles River, Wilmington, MA) weighing 280-350 gm were anesthetized using halothane administered through a face mask and placed in a stereotaxic apparatus with the nose bar set at $-11.5 \mathrm{~mm}$, after which halothane was administered through a nose cone. A 26 gauge guide cannula with threaded plastic sleeves (Plastics One, Roanoke, VA) was cemented into place over MS (anterior, -0.9 , lateral, \pm 0.9 , ventral, -2.4 ) at an angle of $4^{\circ}$ from vertical (in the coronal plane) to avoid damage to the superior sagittal sinus and to minimize damage to ascending fibers of passage that traverse the medial extent of MS. When appropriate, EEG and EMG electrodes were implanted, as described below. The cannula and EEG/EMG electrodes were then cemented into position with Cranioplastic acrylic (Plastics One). After cannula implant, a stainless-steel wire stylet was inserted into and tightly attached to the cannula via a plastic connector (Plastics One). After surgery, the animals were housed in pairs for 5-10 d before testing.

Drugs/intratissue infusions. On the day before testing, pairs of animals were transferred to testing chambers where they were housed individually. The Plexiglas testing chamber $(32 \times 32 \times 40 \mathrm{~cm})$ was housed in a wooden, sound-attenuated outer chamber containing a $15 \mathrm{~W}$ light bulb on a 12:12 hr cycle, a speaker through which white noise $(80 \mathrm{~dB})$ was played, and a $12 \mathrm{~V}$ fan run at reduced speed attached to the rear of the chamber to provide adequate air circulation. There were two $10 \mathrm{~cm}$ holes in the outer chamber: one in the center of the top panel of the chamber to permit infusion lines and EEG cables to exit the chamber and one in the front of the chamber to permit videotaping of the animal. The stylet was removed, and a stainless-steel coil spring was threaded onto the cannula via a plastic connector (Plastics One). The other end of the spring was attached to a liquid swivel (Instech Laboratories, Plymouth Meeting, PA) held in a counterbalance outside the outer chamber. For animals implanted with EEG/EMG electrodes, the FET-headstage and cable were attached at this time and connected to the counterbalance. The animals were fed and given water ad libitum.

On the day of testing, between 8:00 A.M. and 10:00 AM, a 33 gauge needle was connected to a length of PE20 tubing containing water via a 26 gauge piece of stainless-steel tubing cemented to the 33 gauge needle. The PE20 tubing and needle were housed within a stainless-steel coil spring, the distal end of which was attached to the outlet of the liquid swivel via a 25 gauge connector. The inlet of the liquid swivel was connected to a $10 \mu \mathrm{l}$ syringe via a length of PE20 tubing filled with water. An air bubble was placed in the tubing above the liquid swivel to permit visualization of fluid displacement during advancement of the syringe plunger. The needle and tubing were then loaded with 3-5 $\mu$ l of vehicle (PBS containing 2\% Pontamine Sky Blue dye) or ISO (Sigma, St. Louis, MO) dissolved in vehicle $(25 \mu \mathrm{g} / \mathrm{ml})$. An $\sim 50 \mathrm{nl}$ air bubble was used to separate vehicle/ISO from water contained within the PE20 tubing. The plunger of the syringe was advanced by a microprocessor-controlled infusion pump (Harvard Apparatus, South Natick, MA). The stainlesssteel coil spring, connected the previous day, was disconnected, and the 33 gauge needle was inserted into the cannula and secured via a plastic threaded sleeve attached to the stainless-steel coil spring. Usually, this was performed without handling the animal. After needle insertion, the doors to the testing chamber and sound-attenuation chamber were closed. Infusions $(150 \mathrm{nl})$ were made over a 1 min period. The travel of the air bubble was assessed visually, using marks made on the PE20 tubing above the liquid swivel.
If no effect of ISO was evident within 10 min after infusion $(\sim 50 \%$ of the cases), a second infusion was performed. This strategy was based on previous observations of the electrophysiological effects of similar volume peri-LC infusions of both a cholinergic agonist and an $\alpha_{2}$-agonist that indicated that in a substantial proportion of cases, the first infusion after needle insertion and a subsequent delay was often substantially less effective than succeeding infusions (Berridge and Foote, 1991; Berridge et al., 1993). For all vehicle infusions, two infusions were performed, separated by $10 \mathrm{~min}$. Behavioral and EEG/EMG recordings were scored for the $60 \mathrm{~min}$ immediately preceding infusions and the $90 \mathrm{~min}$ immediately after the termination of the last infusion (i.e., the second infusion in those cases in which two infusions were performed).

EEG and EMG recording and analyses. Bipolar electrodes were used to record cortical (ECoG), as described previously (Berridge and Foote, 1991). In a limited number of cases, bipolar electrodes were used to record hippocampal EEG (HEEG) simultaneously with ECoG. In animals in which HEEG was not recorded, EMG was recorded using two 3 $\mathrm{cm}$ lengths of insulated, flexible wire (Cooner Wire, Chatsworth, CA) threaded into the neck muscle and positioned such that an $\sim 3 \mathrm{~mm}$ length of exposed wire was in direct contact with muscle. The wire was tied in a knot to hold the exposed length of wire in contact with the muscle, and the skin was sutured. A screw electrode was placed over the cerebellum and served as ground. The free ends of the EEG, EMG, and ground electrodes were inserted into a five pin plastic connector that was cemented in place, along with the cannula, using acrylic cement (Plastics One). EEG and EMG signals were amplified, filtered $(0.3-50.0 \mathrm{~Hz}$ bandpass), and recorded continuously on a polygraph and on VCR recording tape (Vetter Instruments, Rebersburg, PA) using methods similar to those described previously (Berridge and Foote, 1991), except that a four channel headstage FET amplifier was used in addition to standard EEG amplifiers.

ECoG and EMG were scored for the following behavioral state categories: (1) slow-wave sleep (high-voltage ECoG, low-voltage EMG); (2) REM sleep (low-voltage ECoG combined with EMG activity $\sim 50 \%$ lower amplitude than that observed in slow-wave sleep, with occasional short-duration, large-amplitude deflections attributable to muscle twitches); (3) quiet-waking (low-voltage ECoG with EMG activity of an average amplitude twice that observed in slow-wave sleep); (4) active-waking (low-voltage ECoG, sustained high-voltage EMG of approximately twice that observed in quiet waking, with frequent movement deflections). The combined use of ECoG and EMG or HEEG measures permits discrimination between quiet waking and the desynchronized ECoG activity that has been reported to occur occasionally in sleep, in that this ECoG activation is not accompanied by HEEG theta or EMG activation (Bergmann et al., 1987). To be scored as a distinct epoch, the appropriate EEG and EMG activity patterns needed to persist for a minimum of $15 \mathrm{sec}$. The time spent in each state was scored and totaled for the five $30 \mathrm{~min}$ epochs of the observation period. These included the two segments immediately before infusions (PRE1 $=0-30 \mathrm{~min}$; PRE2 $=30-60 \mathrm{~min}$ ) and the three segments that followed the infusions (POST1 $=60-90 \mathrm{~min}$; POST2 = 90-120 min; POST3 = 120-150 min).

Behavioral analyses. Behavior was videotaped using a black and white, low-level illumination video camera (Panasonic WV-BL2000) positioned in the hole in the door of the outer chamber. Behavioral and EEG data were recorded onto videorecording tape using a modified VCR (Vetter, Model 620). The output of the camera was sent to a time and date imprinter, a black and white monitor, and the VCR. Behavior was recorded continuously starting 30-60 min after insertion of the infusion needle, at a point at which the animals were no longer behaviorally active. Behavior was scored from videotape by a trained observer using a computer-based event recorder (Noldus Information, Wageningen, The Netherlands). The following behaviors were scored for all animals whether or not they were scored for electroencephalographic measures: (1) asleep: body resting on floor, head resting on floor; (2) quiet awake: head raised off of floor, body resting on floor; (3) body up: any point in which the body was raised off of floor and the animal was not engaged in any of the scored behaviors (grooming, rears, eating, drinking) other than horizontal locomotion; (4) grooming; (5) rears (both free and wall); (6) quadrant entries: a measure of horizontal locomotion defined by hind legs crossing into a new quadrant; (7) eating; (8) drinking; (9) total time spent awake: defined as the total observation period minus the time spent asleep. The frequency and duration of all behaviors, except quadrant entries (frequency only), were scored for each of the five consecutive 30 min epochs of the experiment.

Statistical analyses. The effects of the three MS treatments (needle 
insertion/no infusion; MS vehicle; MS ISO) on behavioral measures were statistically analyzed using a two-way ANOVA with time as a repeatedmeasures variable (five levels corresponding to five half-hour epochs: the first two epochs corresponding to the preinfusion portions and the last three epochs corresponding to postinfusion portions of the experiment) and treatment as a between-subjects variable (three levels corresponding to the three different treatments). The effects of MS ISO on EEG/EMGderived measures of behavioral state were analyzed across the five $30 \mathrm{~min}$ epochs using repeated-measures one-way ANOVA (time $=$ within subjects factor). When statistical significance was indicated $(p<0.05)$, post hoc analyses were conducted using Duncan's multiple-range test (between-subject analyses) or means-comparison contrasts (withinsubject analyses).

Histology. After each experiment, the animal was deeply anesthetized and perfused with $4 \%$ formaldehyde. The brain was removed and placed in perfusion solution. After a minimum of $24 \mathrm{hr}$, the brain was frozen, and $40-\mu \mathrm{m}$ sections were cut and collected through MS and the other areas in which infusions were made. The sections were stained with Neutral-Red dye for subsequent examination of the infusion sites. The extent of the spread of Pontamine Sky Blue dye in freshly sectioned tissue was recorded.

Data selection criteria. Data were included in the analyses for all cases, and only in those cases in which EEG electrode placements were accurate were EEG recordings electrically adequate and could accurate placement of the infusion needle be anatomically verified.

\section{RESULTS \\ General observations}

Rats transferred to the testing chamber appeared to rapidly adapt to the new environment, with the initial exploratory period lasting 30-90 min. Typically, rats were observed to be resting on the morning of testing. Although the animals woke upon opening of the sound-attenuated chamber, insertion of the 33 gauge infusion needle was often accomplished without the need to handle the animal. However, regardless of whether the animal was handled during needle insertion, the behavioral-activating effects of the process of needle insertion quickly dissipated, such that within 30-90 min of needle insertion, animals were resting with head down and eyes closed. Insertion of the needle did not produce overt adverse behavioral effects.

All infusions were performed after the collection of at least 60 min of baseline behavior (and EEG/EMG when appropriate) and at a point when the animal was resting (body and head resting on the floor of chamber). In animals in which EEG and EMG were recorded, at this point, large-amplitude, slow-wave ECoG activity, mixed-frequency HEEG activity, and low-voltage EMG activity were present (i.e., slow-wave sleep).

Histological analyses indicated that needle insertion did not produce substantially greater tissue damage than that observed in previous studies conducted in anesthetized rat (data not shown) (for discussion, see Berridge et al., 1996). In cases in which the infusion was placed in the general region of MS, the spread of dye was comparable to that observed in anesthetized animals, with dye observed throughout the ventral half of the region defined as MS and extending nearly throughout the anterior-posterior extent of MS, as observed in anesthetized rat (for discussion, see Berridge et al., 1996). As used here, MS refers to the general region of the basal forebrain containing the medial septum, the vertical limb of the diagonal band of Broca, the islands of Calleja, and the shell region of the nucleus accumbens. In a number of ISO infusion experiments, no dye was visible on sectioning of the tissue, presumably because of problems with the liquid swivel. Previous studies in which a liquid swivel was not used demonstrated that this concentration of dye is readily apparent in freshly sectioned tissue even with infusion volumes as small as $35 \mathrm{nl}$ (Berridge et al., 1993, 1996). Therefore, it is concluded that the absence of dye indicated that drug did not enter the brain. These cases (needle insertion/no infusion) were analyzed separately from the vehicle- and drug-infusion groups, with the pre- and postinfusion epochs measured from the point at which the infusion pump was turned off.

\section{Definition of MS boundaries}

The effects of ISO infusions made into and adjacent to MS on behavioral indices of waking (derived from videotaped records of behavioral activity) were examined in a total of 26 animals (see below). For all experiments, behavior was recorded for $60 \mathrm{~min}$ before and $90 \mathrm{~min}$ after infusions (see Materials and Methods). ISO infusions into the general region of MS consistently elicited substantial increases in waking behavior observed per half-hour interval as compared with vehicle-infusion or needle insertion/no infusion animals (Fig. 1) (see below). The distribution of infusion sites that did or did not result in substantial time spent awake identifies a region of the basal forebrain encompassing the medial septum in which ISO infusions act to alter behavioral state. The boundaries of this region are identical to those observed in a previous study documenting EEG-activating effects of ISO infusions into this region of the basal forebrain in the halothaneanesthetized rat (Berridge et al., 1996). Thus, quantitative analyses were conducted on those animals in which the ventral tip of the infusion needle was located within this region. This area, indicated in Figure 1 by the dashed line, encompasses the majority of ISO infusion sites that appeared to increase time spent awake, and excludes the majority of sites at which infusions appeared to elicit marginal or no effects on waking. For all groups, data from a particular case were included in MS or non-MS infusion groups solely on the basis of needle placement assessed from histological analyses conducted by personnel blind to the behavioral effects of the infusion.

\section{Behavioral effects of ISO infusions, vehicle infusions, and needle insertion/no infusion in MS}

Analyses were conducted on the 26 animals receiving MS-ISO infusions, the 12 animals that received MS vehicle infusions, and the 13 needle insertion/no infusion animals, all of which had the ventral tip of infusion needles placed within the dashed lines of Figure 1. Analyses were conducted across the five $30 \mathrm{~min}$ observational epochs: $\operatorname{PRE} 1(t=0-30 \mathrm{~min}), \operatorname{PRE} 2(t=30-60 \mathrm{~min})$, POST1 $(t=60-90 \mathrm{~min}), \operatorname{POST} 2(t=90-120 \mathrm{~min}), \operatorname{POST} 3(t=$ $120-150 \mathrm{~min})$. The effects of infusions on behavioral state, as defined by behavioral measures, are depicted in Figure 2. ANOVA indicated a significant main effect of treatment $\left(F_{(2,240)}\right.$ $=48.9, p<0.0001)$, time $\left(F_{(4,240)}=3.8, p<0.01\right)$, and a significant treatment $\times$ time interaction $\left(F_{(8,240)}=10.7, p<\right.$ $0.0001)$ on total time spent awake and asleep (treatment, $F_{(2,240)}$ $=48.9, p<0.0001$; time $F_{(4,240)}=3.8, p<0.01$; treatment $\times$ time $\left.F_{(8,240)}=10.7, p<0.0001\right)$. Post hoc analyses indicated that total time spent awake was significantly increased only in the MS-ISO group during postinfusion epochs, POST1-POST3 (compared with either PRE1 or PRE2 of the ISO-MS group or as compared with the postinfusion epochs of the vehicle or needle insertion/no infusion groups). For example, total time spent awake was increased from $190 \pm 41 \mathrm{sec}$ during PRE1 to $1076 \pm 75 \mathrm{sec}$ during POST1. Conversely, time spent asleep was significantly decreased during postinfusion epochs (PRE1, $1610 \pm 41 \mathrm{sec}$; POST1, $723 \pm$ $76 \mathrm{sec}$ ) (Fig. 2).

As shown in Figures 2 and 3, ISO-induced waking was associated with significant increases in time spent engaged in the following behaviors: quiet awake $\left(F_{(2,240)}=44.1, p<0.0001\right)$, body 
Figure 1. Schematic depiction of the location of each ISO infusion with a numeral indicating the effect of each infusion on total time spent awake. $\mathrm{Nu}$ merals specify the appropriate time range $(1=0-500 \mathrm{sec} ; 2=500-1000$ $\mathrm{sec} ; 3=1000-2000 \mathrm{sec} ; 4=2000-3000$ sec; $5=>3000 \mathrm{sec}$ ) for total time spent awake during the $60 \mathrm{~min}$ postinfusion interval for each animal. Vehicletreated animals displayed a mean total time awake in this period of $302 \pm 88$ $\mathrm{sec}$ with a range of $125-1098 \mathrm{sec}$. These infusions identify a region within which ISO infusions increase waking that encompasses the medial septum, the vertical limb of the diagonal band of Broca, the islands of Calleja, and posterior portions of the shell region of the nucleus accumbens. This region is identified by the dotted line border and is collectively referred to as MS. Infusions outside this region were substantially less effective at increasing waking beyond that observed in preinfusion epochs or in vehicle-treated animals. $A C$, Anterior commissure; $C C$, corpus callosum; $C P$, caudate-putamen; $I C$, internal capsule; $L S$, lateral septum; $L V$, lateral ventricle; $M S$, medial septum; $N A$, nucleus accumbens. Each level is separated by $250 \mu \mathrm{m}$, with the most anterior section in the top left panel (modified from Swanson, 1992).

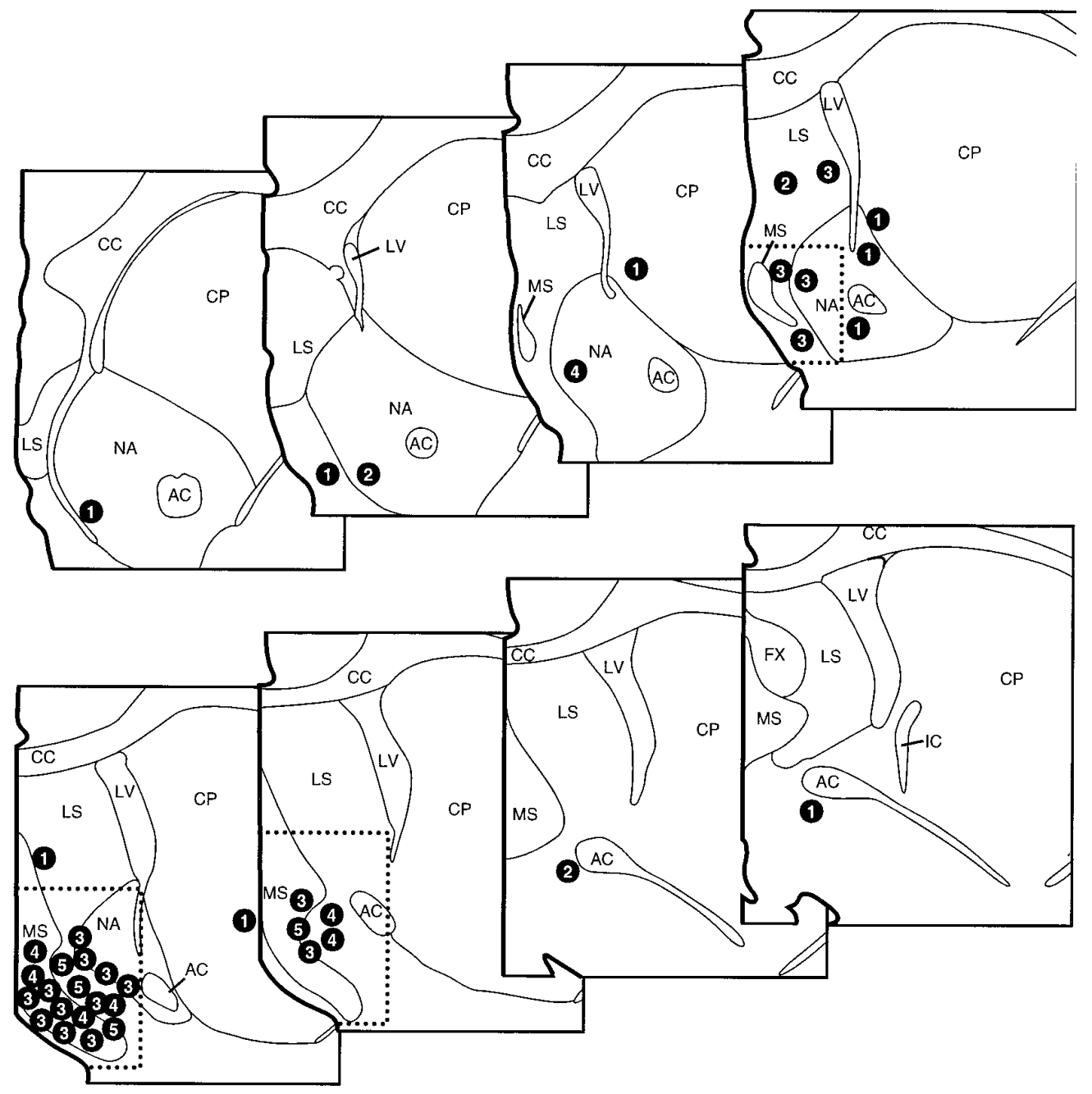

up $\left(F_{(2,240)}=25.9, p<0.0001\right)$, rears $\left(F_{(2,240)}=9.2, p<0.0001\right)$, eating $\left(F_{(2,240)}=3.5, p<0.05\right)$, and grooming $\left(F_{(2,240)}=18.22\right.$, $p<0.0001)$. There was a trend toward increased duration of drinking behavior in ISO-treated animals, which was not statistically significant $\left(F_{(2,240)}=2.6, p=0.08\right)$. For each behavior for which a significant effect of treatment was observed, there was a significant treatment $\times$ time interaction (rears, $F_{(8,240)}=2.1, p<$ 0.05 ; quiet awake, $F_{(8,240)}=6.3, p<0.0001$; body up, $F_{(8,240)}=$ $8.3, p<0.0001$; eating $F_{(8,240)}=3.4, p<0.01$; grooming $F_{(8,240)}$ $=3.6, p<0.001)$, such that scores for postinfusion intervals differed significantly from those for preinfusion intervals and that those for the two preinfusion intervals did not differ significantly. The increase in time spent eating was significant only in the first half-hour after the infusion. Duration of rears was significantly increased in the first two half-hour epochs after ISO infusions, whereas duration of grooming was significantly increased in the three half-hour epochs after ISO infusions.

As observed for duration of behavioral responses, MS-ISO infusions significantly increased the frequency of most behaviors scored (Fig. 4). Specifically, ISO infusions significantly increased the occurrences of quiet awake, (treatment, $F_{(2,240)}=47.4, p<$ 0.0001 ; treatment $\times$ time $\left.F_{(8,240)}=11.5, p<0.0001\right)$; body up (treatment, $F_{(2,240)}=29.8, p<0.0001$; treatment $\times$ time $F_{(8,240)}$ $=7.6, p<0.0001$ ); rears (treatment, $F_{(2,240)}=8.4, p<0.0005$; treatment $\times$ time $\left.F_{(8,240)}=2.6, p<0.01\right)$; quadrant entries (treatment, $F_{(2,240)}=26.3, p<0.0001$; treatment $\times$ time $F_{(8,240)}$ $=6.9, p<0.0001$ ); eating (treatment, $F_{(2,240)}=7.7, p<0.001$; treatment $\times$ time $\left.F_{(8,240)}=3.8, p<0.0005\right)$; and grooming (treatment, $F_{(2,240)}=25.3, p<0.0001$; treatment $\times$ time $F_{(8,240)}$ $=5.1, p<0.0001)$. MS ISO did not significantly alter the frequency of drinking (treatment, $F_{(2,240)}=2.7, p=0.07$; treatment $\times$ time $\left.F_{(8,240)}=1.3, p=0.14\right)$.

Post hoc analyses indicated that none of the behavioral measures varied significantly over the course of the experiment in either the needle insertion/no infusion group $(n=13)$ or the MS vehicle infusion group $(n=12)$ (Figs. $2-4)$. Further, there were no significant differences in any of the behavioral categories between any of the three treatment groups during the preinfusion portions of the experiment (Figs. 2-4). Finally, there were no significant differences in any of the behavioral categories between the needle insertion/no infusion group and vehicle-infusion group during the postinfusion intervals of the experiment (Figs. 2-4).

Qualitatively, the specific behaviors and behavioral patterns displayed by MS-ISO animals were not readily distinguishable from those of nontreated animals. In cases $(\sim 60 \%)$ in which a single infusion was performed, behavioral indices of waking were observed within 4-10 min. Similar latencies were observed in cases in which a second infusion was performed 10 min after the first. Thus, latency for eliciting waking behaviors ranged from 4 min to a possible maximum of $20 \mathrm{~min}$. 

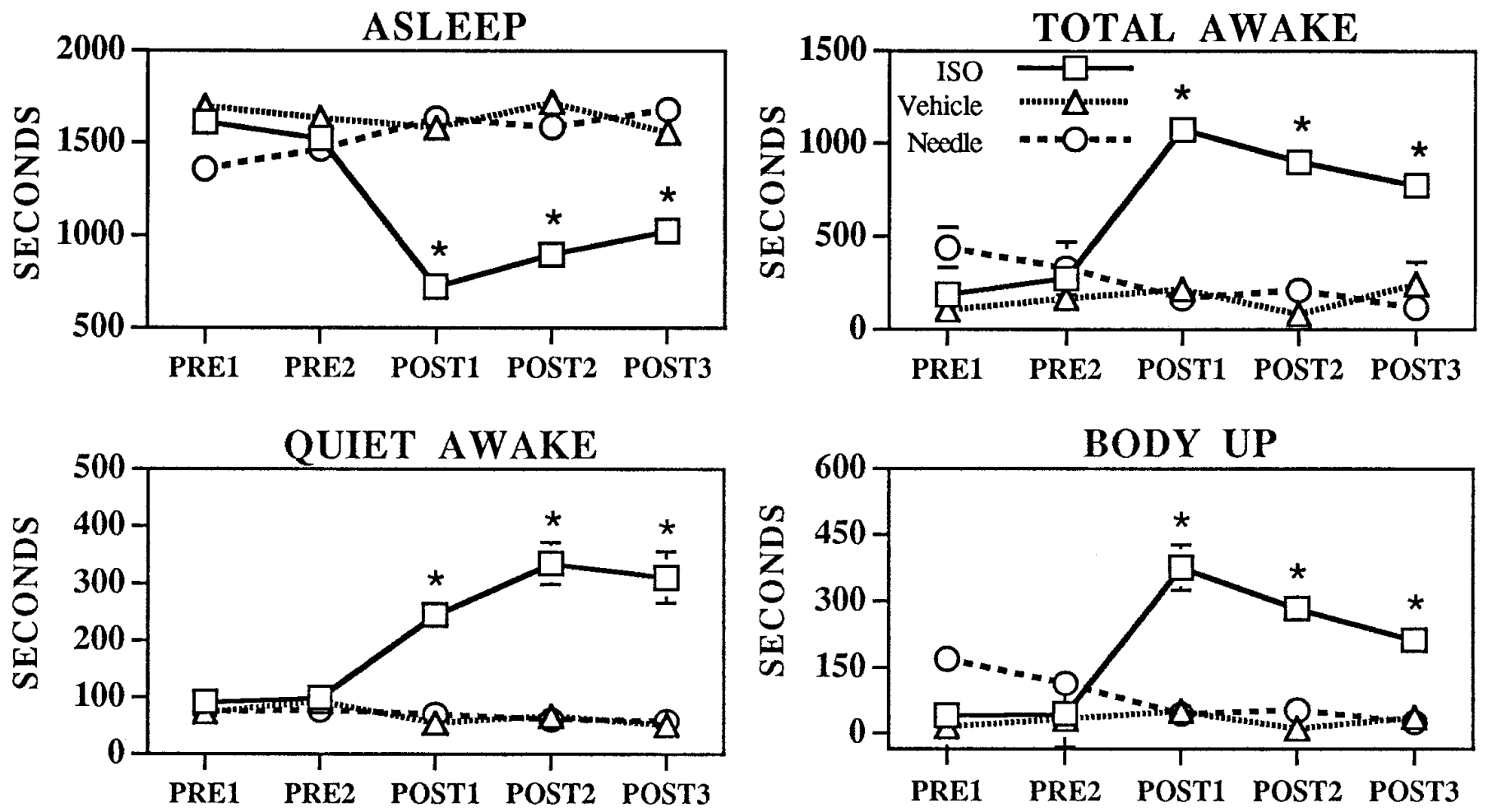

Figure 2. Effects of MS needle insertion/no infusion (Needle, circles), MS vehicle infusions (Vehicle, triangles), and MS-ISO infusions (ISO, squares) on time spent asleep, awake, quiet awake, or body up (a subset of active waking), defined on the basis of behavioral measures. Symbols represent mean \pm SEM of time (in seconds) spent in specific behavioral categories across the five half-hour epochs of the experiment. PRE1 and PRE2 represent 30 min preinfusion portions of the experiment. POST1-POST3 represent 30 min postinfusion epochs. Where no error bars are visible, the magnitude of the SEM fell within the range corresponding to the dimensions of the symbol. There were no significant differences between vehicle-treated and needle insertion/no infusion groups for any time interval. There were no significant differences between any of the groups during the preinfusion epochs. ${ }^{*} p<0.01$ compared with PRE1; ${ }^{+} p<0.05$ compared with PRE1.

In a number of cases $(n=11)$, an infusion was made $120 \mathrm{~min}$ after the first infusion $(t=180 \mathrm{~min})$. In these cases, the animals were typically observed to be resting (determined on the basis of behavioral observations) at the time of the infusion. The effectiveness of this infusion was comparable to the first (data not shown).

\section{ECoG, HEEG, and EMG effects of ISO infusions into MS}

To assess better the effects of ISO-induced alterations in behavioral state, ECoG and HEEG or EMG were recorded in a subset of animals that received ISO infusions that were included in the behavioral analyses described above. In six cases, ECoG and HEEG were simultaneously recorded. Two of these cases were not included in the behavioral analyses described above because of problems with the videorecordings. Of these six animals, four animals had both ECoG and HEEG electrodes implanted ipsilateral to the infusion site whereas, in two cases, the HEEG electrode was implanted contralateral to the infusion site and the ECoG electrode.

In an additional 21 cases, ECoG and EMG activity was recorded simultaneously. Of this latter group, eight cases had needle placements within MS and dye was present in the tissue, three cases had needle placements within MS but no dye present in the tissue, and six cases had needle placement adjacent to MS. In the remaining four cases, the infusion needle was loaded with vehicle and placed within MS, and dye was present in the tissue. The design of these experiments was identical to that described above, other than for implantation of EEG and EMG electrodes (see Materials and Methods).

Needle insertion alone or vehicle infusions into MS lacked consistent, obvious effects on EEG, EMG, or behavioral indices of waking (data not shown). In animals in which ECoG and HEEG were simultaneously recorded, ISO infusions that elicited increased behavioral indices of waking elicited an activation of both ECoG and HEEG; there was a shift in ECoG activity from slow-wave, large-amplitude to high-frequency, low-amplitude activity (Fig. 5) and a shift in HEEG activity from mixed frequency activity to theta activity (highly regular, $\sim 9 \mathrm{~Hz}$ activity). Within the limits of temporal resolution $(\sim 1-2 \mathrm{sec})$, the activation of both ECoG and HEEG appeared to occur simultaneously.

Slow-wave sleep, REM sleep, quiet awake, active awake, and total time spent awake were determined on the basis of cortical EEG and EMG activity patterns (see Materials and Methods). The effects of MS-ISO infusions on EEG/EMG-defined behavioral states are shown in Figures 5 and 6. Compatible with the behavioral data described above, before infusion, animals spent the majority of the time in slow-wave sleep and approximately equal time in REM sleep and total time spent awake (quiet awake: PRE1, mean $=87 \pm 54$; PRE2, mean $=146 \pm 52$; active awake: PRE1, mean $=133 \pm 75$, PRE2, mean $=213 \pm 131$ ). After ISO infusions, slow-wave sleep was significantly decreased $\left(F_{(4,7)}=22.4, p<0.0001\right)$ and total time spent awake was significantly increased $\left(F_{(4,7)}=26.86, p<0.0001\right.$; POST1, mean $=1156 \pm 125 ;$ POST2, mean $=1424 \pm 124 ;$ POST3, 

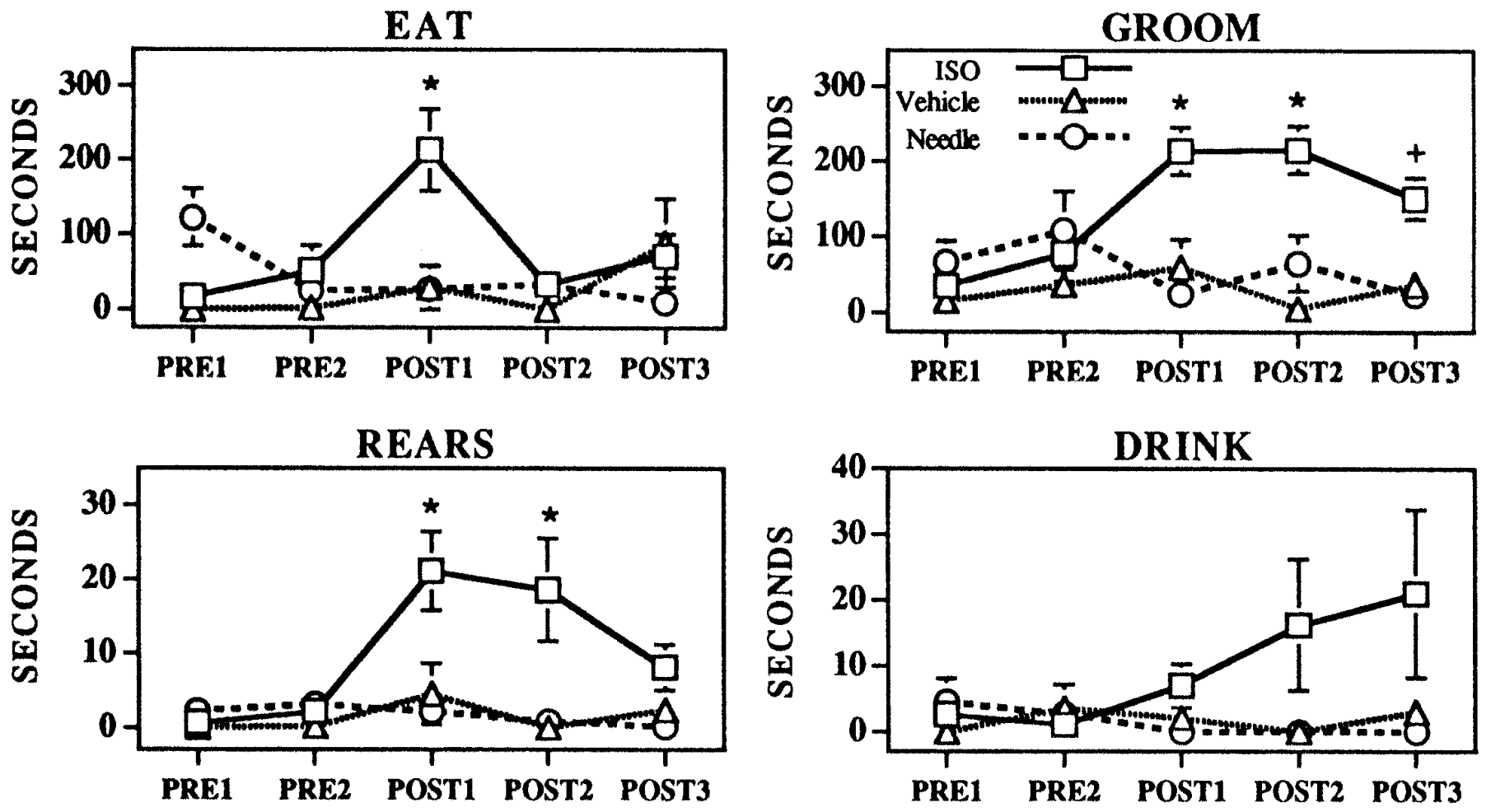

Figure 3. Effects of MS needle insertion/no infusion (Needle, circles), MS vehicle infusions (Vehicle, triangles), and MS-ISO infusions (ISO, squares) on the time spent eating, grooming, rearing, and drinking. Symbols represent mean \pm SEM of time (in seconds) spent engaged in specific behaviors across the 5 half-hour epochs of the experiment. PRE1 and PRE2 represent preinfusion portions of the experiment. POST1-POST3 represent postinfusion epochs. Where there are no visible error bars, the magnitude of the SEM fell within the range corresponding to the dimensions of the symbol. There were no significant differences between vehicle-treated and needle insertion/no infusion groups for any time interval. There were no significant differences between any of the groups during the preinfusion epochs. ${ }^{*} p<0.01$ compared with PRE1; ${ }^{+} p<0.05$ compared with PRE1.

mean $=1240 \pm 130)$. The effects of ISO infusions on total time awake resulted from significant increases in both quiet $\left(F_{(4,28)}=\right.$ $10.0, p<0.0001 ;$ PRE1, mean $=87 \pm 54 ;$ PRE2, mean $=146 \pm$ $52 ;$ POST1, mean $=295 \pm 72 ;$ POST2, mean $=551 \pm 84 ;$ POST3, mean $=582 \pm 90)$ and active awake $\left(F_{(4,28)}=10.2, p<0.0001\right.$ PRE1, mean $=133 \pm 75 ;$ PRE2, mean $=213 \pm 135 ;$ POST1, mean $=860 \pm 140 ;$ POST 2 , mean $=872 \pm 114$; POST3, mean $=$ $657 \pm 90)$. Time spent in quiet awake and active awake was significantly increased in each epoch after ISO infusions compared with either preinfusion epoch. Quiet waking was significantly lower in POST1 as compared with either POST2 or POST3 epochs. Although active waking appeared to decrease in POST3, this was not statistically significant. The EEG/EMG responses either coincided with behavioral activation $(n=3)$ or preceded it by $\sim 10 \mathrm{sec}$ to $320 \mathrm{sec}(n=7)$.

EMG and EEG measures revealed an apparently larger effect of MS ISO on total time spent awake than that documented using behavioral measures alone. This appeared to reflect the fact that during the latter portions of the ISO-induced behavioral response ( $t=90-150 \mathrm{~min})$, the animals would often lie down with head resting on the floor and, thus, behaviorally appear to be asleep. This resting behavior was frequently interrupted by brief (1-5 $\mathrm{min}$ ) periods in which the animals would raise their head off of the floor or become behaviorally active (compare Figs. 2 and 6). Often, during this portion of the response, although the animals appeared to be asleep on the basis of behavioral measures, EEG and EMG remained activated, indicating that the animal was awake (quiet awake) and not in slow-wave sleep.

ISO infusions into MS resulted in a near-complete suppression of REM sleep $\left(F_{(4,7)}=11.9, p<0.0001\right)$ (Fig. 6). In terms of percent change from preinfusion baseline, the suppression of REM sleep represents the largest magnitude effect of MS-ISO infusions on any of the scored behavioral states.

\section{Behavioral and EEG effects of ISO infusions outside of MS}

The results described above indicate that the region defined as MS (see above) is an area in which ISO infusions elicit substantial and sustained changes in behavioral and EEG state. To verify that the behavioral effects of these infusions were not attributable to diffusion through surrounding tissue and/or ventricular space and subsequent action of ISO within adjacent structures, ISO infusions were made into nearby sites. These included the nucleus accumbens $(n=6)$; the striatum, at a distance from the lateral ventricle similar to that of the effective MS infusions $(n=3)$; the lateral septum $(n=5)$; and the region immediately posterior to MS $(n=4)$.

As observed in the halothane-anesthetized preparation and as indicated in Figure 1, infusions of ISO outside of MS into striatum, core subregion, or anterior nucleus accumbens or posterior to MS did not elicit consistent alteration in any of the behavioral measures. Although ISO infusions into the lateral septum appeared to increase waking behavior, the magnitude and duration of this effect was consistently and substantially less than that observed for infusions placed more ventrally, suggesting that the lateral septum is not the primary site at which ISO infusions enhance waking. 

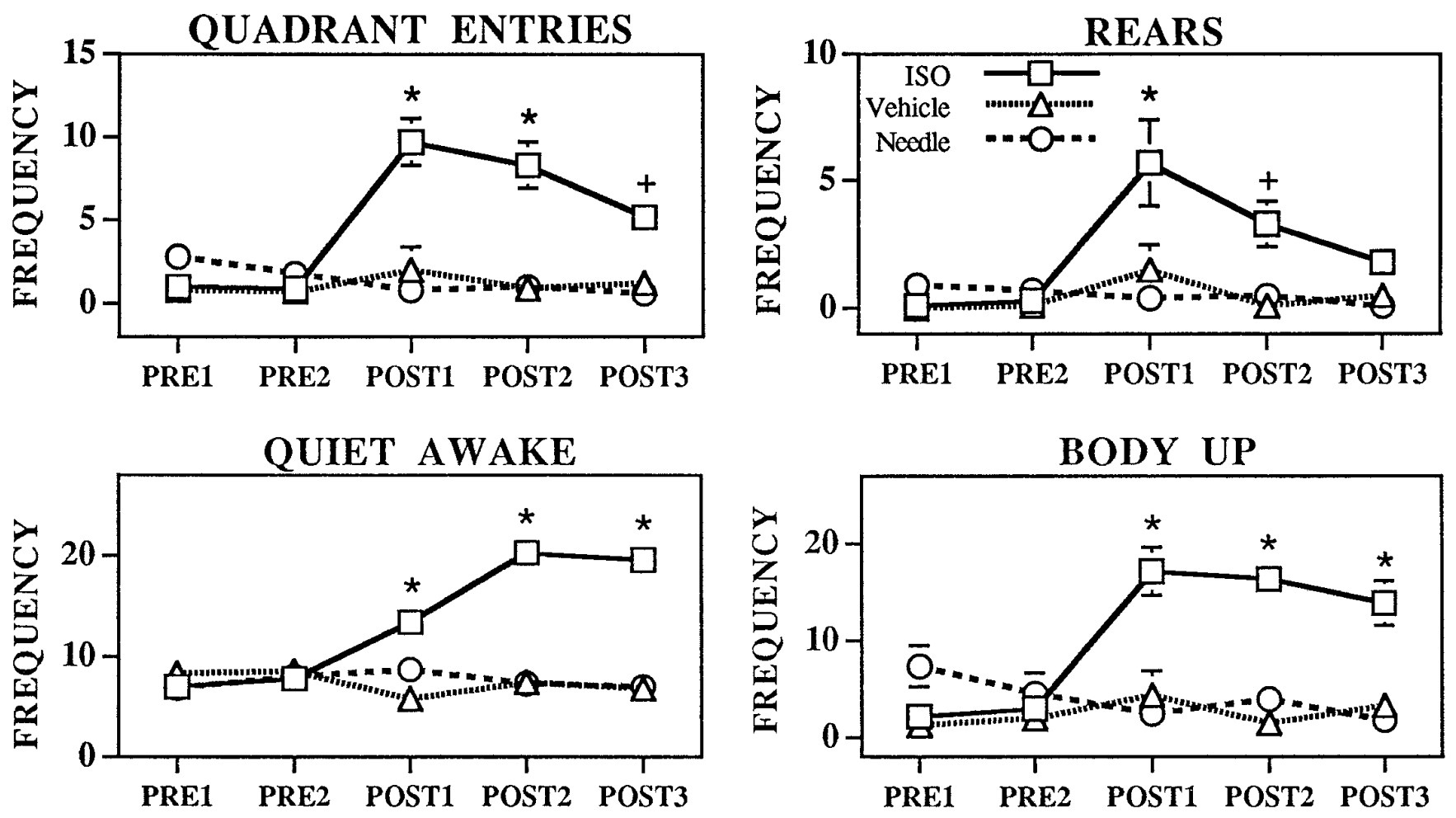

Figure 4. Effects of MS needle insertion/no infusion (Needle, circles), MS vehicle infusions (Vehicle, triangles), and MS-ISO infusions (ISO, squares) on the frequency of eating, grooming, rearing, and drinking. Symbols represent mean frequency/occurrence \pm SEM of each behavior per 30 min epoch. PRE1 and PRE2 represent preinfusion portions of the experiment. POST1-POST3 represent postinfusion epochs. Where no visible error bars occur, the magnitude of the SEM fell within the range corresponding to the dimensions of the symbol. There were no significant differences between vehicle-treated and needle insertion/no infusion groups for any time interval. There were no significant differences between any of the groups during the preinfusion epochs. ${ }^{*} p<0.01$ compared with PRE1; ${ }^{+} p<0.05$ compared with PRE1.

\section{DISCUSSION}

The present studies demonstrate that discrete infusions of a noradrenergic $\beta$-agonist into the region of MS elicit consistent substantial enhancement of behavioral, EEG, and EMG measures of waking in the unanesthetized rat. These infusions resulted in the transition from primarily resting behavior associated with large-amplitude, slow-wave activity in ECoG and low-voltage EMG activity (slow-wave sleep) to long bouts of waking behavior associated with activation of the ECoG (desynchronized activity) and EMG (high-voltage activity). The EEG/EMG responses either coincided with, or preceded by $\sim 10-320 \mathrm{sec}$, ISO-induced behavioral activation. In general, the individual behavioral responses and the pattern of these responses resembled those observed in normal waking; normally absent behaviors were not observed, whereas behaviors typically observed in waking were evident (e.g., eating, drinking, grooming). As such, the behavioral effects of MS ISO did not appear to be similar to the behavioral activation typically observed after certain pharmacological manipulations such as amphetamine or cocaine administration (Segal, 1975).

It is of interest that MS-ISO infusions that suppressed but did not eliminate slow-wave sleep elicited the near-complete suppression of REM sleep. In terms of percent of preinfusion baseline, suppression of REM sleep was the most profound action of MS-ISO infusions. Thus, during the third 30 min epoch after MS-ISO infusions $(t=120-150 \mathrm{~min})$, waking was increased to $564 \%$, slow-wave sleep was decreased to $42 \%$, and REM sleep was decreased to $3 \%$ of the levels evident during the first halfhour of the preinfusion period. This observation is consistent with hypotheses proposed previously that posit a critical role of LC suppression for the normal emergence of REM sleep (Hobson et al., 1975, 1986).

\section{Site of action}

Previous mapping studies demonstrated that the area defined as MS forms a discrete LC terminal field in terms of the ability of $\beta$-agonists and $\beta$-antagonists to modulate forebrain EEG (Berridge et al., 1996). In the present studies, a similar anatomically restricted distribution of effective ISO infusions sites was observed, indicating that this region of the basal forebrain is a site at which $\beta$-receptors modulate behavioral state. However, this region is anatomically complex, with the medial septum, the vertical limb of the diagonal band of Broca, the shell region of the nucleus accumbens, and the islands of Calleja all within close proximity. Excluding the islands of Calleja, all of these regions receive a moderate to dense noradrenergic innervation (see Berridge et al., 1996) (C. Berridge, T. Stratford, S. Foote, and A. Kelly, unpublished observations). Therefore, effective infusions could alter neuronal activity in a number of efferent paths arising from any one of these structures (for discussion, see Berridge et al., 1996). For example, the behavioral and EEG effects observed after $\beta$-receptor stimulation could depend on septal-diagonal band efferents to cortex and hippocampus (Swanson and Cowan, 1977; Saper, 1984; Stewart et al., 1985), projections from the medial septum or the shell region of the accumbens to intermediate structures involved in modulation of behavioral state such as the hypothalamus (Meibach and Siegel, 1977; Swanson and Cowan, 1979; Mogenson et al., 1983; Groenewegen and Russchen, 1984; Zaborsky et al., 1985; Heimer et al., 1991; Cunningham et al., 


\section{PRE-INFUSION}

ECoG

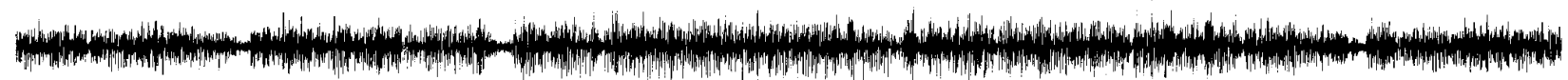

EMG

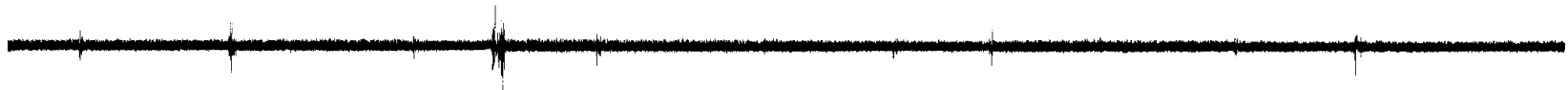

\section{POST-INFUSION}

ECoG

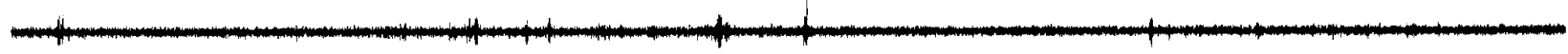

EMG

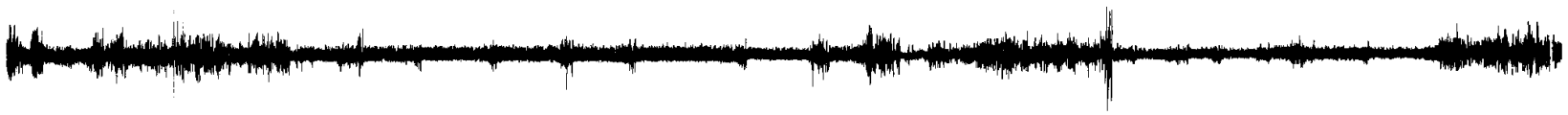

\section{RECOVERY}

ECoG

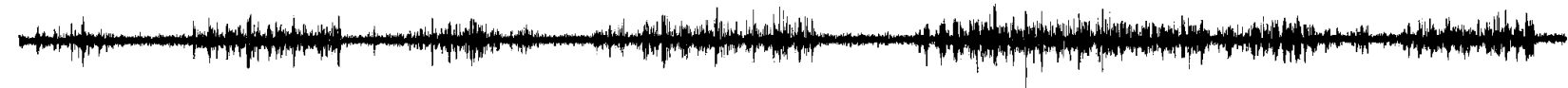

EMG

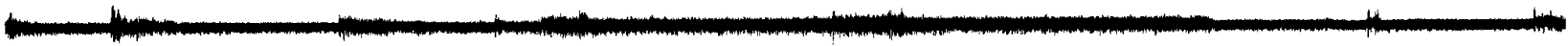

Figure 5. Effects of MS-ISO infusions on ECoG and EMG from a typical experiment. Shown are 10 min traces of ECoG and EMG recorded immediately before, $15 \mathrm{~min}$ after, and $75 \mathrm{~min}$ after an infusion of ISO into MS. Before the infusion, the animal spent the majority of time in slow-wave sleep (resting with large-amplitude, slow-wave activity present in ECoG and low-amplitude activity present in EMG). The most striking postinfusion changes are the decrease in large-amplitude, slow-wave ECoG activity and the increase in EMG amplitude. The latter portions of the behavioral response (RECOVERY) are associated with relatively long bouts of slow-wave ECoG activity interrupted by intermediate-duration epochs of ECoG activation and moderateamplitude EMG activity (quiet waking). Occasionally, these bouts of quiet waking were not accompanied by overt behavioral activity that would have indicated that the animal was awake.

1992; Deutch et al., 1993), or indirect projections from hippocampus to intermediate structures such as hypothalamus (Swanson and Cowan, 1977; Walaas and Fonnum, 1980; Ino et al., 1988).

\section{LC and the modulation of EEG and behavioral state}

The present observations are consistent with the longhypothesized role of the LC noradrenergic system in the modulation of behavioral state (for review, see Vanderwolf and Robinson, 1981). In general, pharmacological suppression of noradrenergic activity increases sedation. Thus, systemic, intracerebroventricular, or intrabrainstem administration of $\alpha_{2^{-}}$ agonists or $\beta$-antagonists increases behavioral and EEG indices of sedation, although technical limitations associated with the manipulations used substantially limit conclusions regarding the specific noradrenergic systems involved (Fink and Irwin, 1981; DeSarro et al., 1987, 1988; Segal et al., 1988). Pharmacological activation of brain noradrenergic receptors has been observed to increase locomotor activity of rats (Segal and Mandell, 1970; Flicker and Geyer, 1982). However, drug administration procedures used in these studies involved handling of the animal, resulting in an awake, alert baseline behavioral state from which to measure drug-induced alterations in be- havior. Therefore, it is unclear whether enhanced locomotor activity observed in these studies reflects changes in arousal/ alertness level per se or alterations in other behavioral processes related to exploration or attention that are superimposed on an alert, awake behavioral state.

Observations obtained with pharmacological manipulations are in conflict with the often-observed minimal effects of destruction of LC or LC efferents on behavioral or EEG indices of arousal (for review, see Vanderwolf and Robinson, 1981). There are at least two mechanisms that likely contribute to this discrepancy. First, the well-documented, damage-induced compensatory responses of noradrenergic systems may minimize lesion-induced functional deficits (Diaz et al., 1978; U'Prichard et al., 1980; Harik, 1984; Hallman and Jonsson, 1984; Berridge and Dunn, 1990). Consistent with this is the observation of time-dependent effects of 6-OHDA lesion of the dorsal noradrenergic bundle on EEG activity; an increase in slow-wave activity was observed initially but had disappeared within $7 \mathrm{~d}$ after the lesion (Lidbrink, 1974). Second, the actions of other ascending systems, such as cholinergic and serotonergic systems, may minimize the consequences of disruption of noradrenergic systems (Jouvet, 1972; 

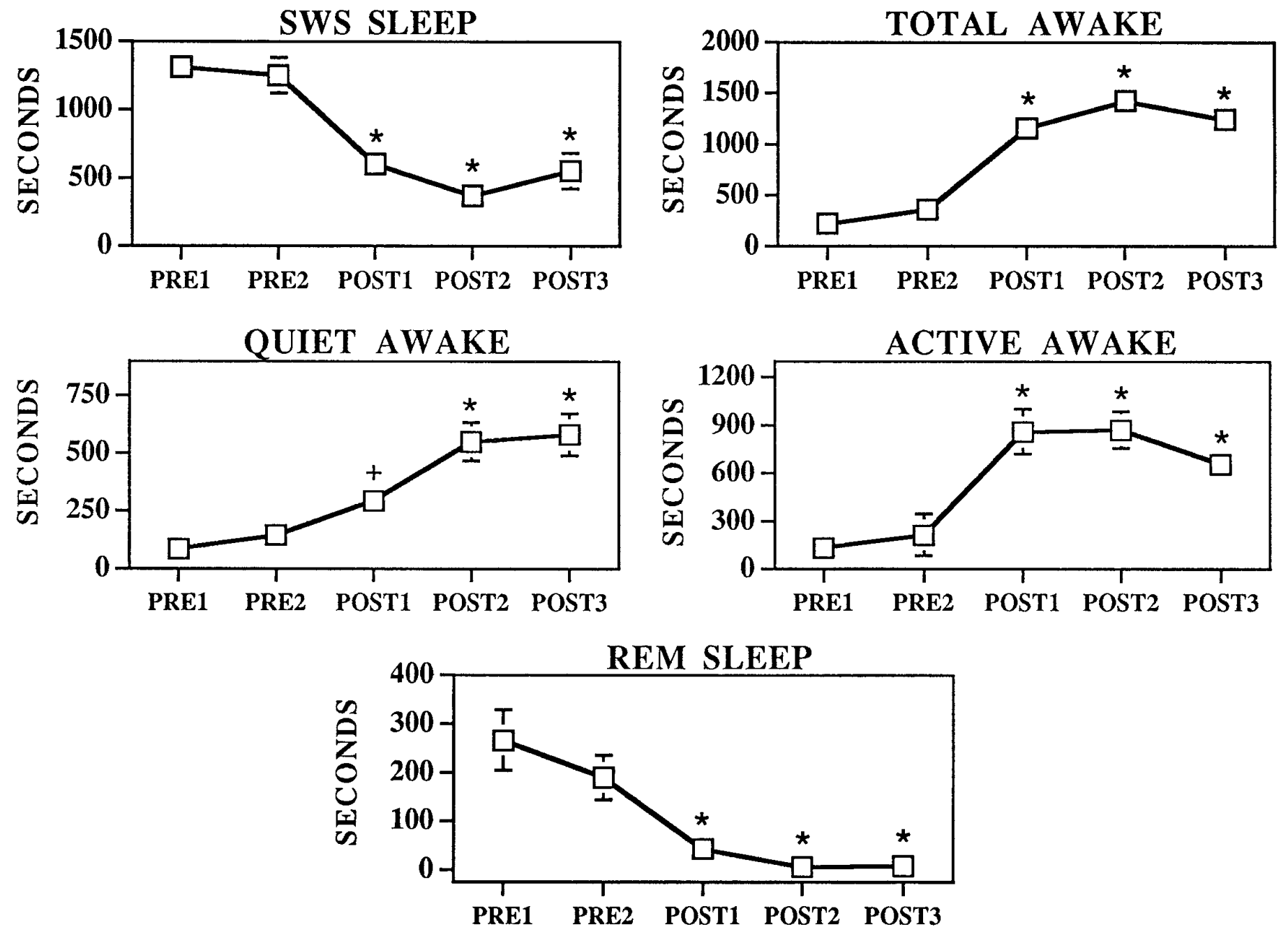

Figure 6. Effects of MS-ISO infusions on REM sleep, slow-wave sleep, quiet waking, active waking, and total time spent awake (quiet waking + active waking), as defined by ECoG and EMG measures. Symbols represent means \pm SEM of time (in seconds) spent in the five different behavioral state categories per $30 \mathrm{~min}$ epoch. PRE1 and PRE2 represent preinfusion portions of the experiment. POST1-POST3 represent postinfusion epochs. The lack of visible error bars indicates that the magnitude of the SEM fell within the range corresponding to the dimensions of the symbol. ${ }^{*} p<0.01$ compared with PRE1; ${ }^{+} p<0.05$ compared with PRE1.

Buzsaki et al., 1988; Vanderwolf, 1988; Steriade et al., 1990; Steriade and McCarley, 1990; Metherate et al., 1992).

Most pharmacological approaches used to study LC function through direct manipulations of LC lack sufficient anatomical specificity because of the small size of the nucleus. The use of electrophysiological recordings to guide infusions of drugs that alter LC discharge rates permits the use of substantially smaller infusion volumes, increasing the anatomical resolution of intrabrainstem infusions (Adams and Foote, 1988; Berridge and Foote, 1991). The use of this approach in halothane-anesthetized rat demonstrated forebrain EEG activation is causally related to enhanced LC neuronal activity (Berridge and Foote, 1991; Berridge et al., 1993; Page et al., 1993).

The region defined as MS receives a dense noradrenergic innervation, the majority of which arises from LC (Segal, 1976; Gaspar et al., 1985; Vertes, 1988; Chang, 1989; Zaborsky et al., 1989, 1991; Milner, 1991). Stimulation of $\beta$-receptors within MS increases EEG measures of arousal in the halothane-anesthetized rat, whereas $\beta$-receptor blockade within MS has the opposite effect (Berridge et al., 1996). The present studies demonstrate that MS $\beta$-receptors exert similar modulatory actions on EEG and behavior in the unanesthetized, resting animal. Combined, these observations strongly suggest that a consequence of LC activation is the stimulation of $\beta$-receptors located within MS and the consequent enhancement of behavioral and EEG measures of waking. The actions of $\alpha_{1}$-receptors located within MS on behavioral state remain to be addressed.

Although the present studies demonstrate that activation of MS $\beta$-receptors is sufficient to elicit and maintain waking in the resting rat, the degree to which MS $\beta$-receptors contribute to the induction and maintenance of alert waking across varying environmental conditions remains unclear. Future studies will need to address the relative contributions of noradrenergic, cholinergic, and serotonergic systems to the initiation and maintenance of alert waking.

\section{Actions of LC efferents across LC terminal fields}

LC efferents project widely throughout the neuraxis. Therefore, under normal conditions in which LC neuronal discharge is increased, the arousal-enhancing effects of NE attributable to actions at $\beta$-receptors within MS occur simultaneously with actions of NE in multiple terminal fields, including neocortex and thalamus. In vivo, $\mathrm{NE}$ enhances stimulus-elicited responding of cortical 
neurons relative to basal discharge rates (e.g., enhances signal-tonoise ratio) (Foote et al., 1975; Woodward et al., 1979) whereas, in vitro, $\mathrm{NE}$ induces a shift in firing patterns of thalamic and cortical neurons from a burst mode associated with slow-wave sleep to a single spike mode associated with waking (Pape and McCormick, 1989; McCormick and Pape, 1990). These latter effects involve actions of NE at both $\alpha_{1}$ - and $\beta$-receptors. Combined, these observations suggest that the LC noradrenergic system exerts widespread effects throughout the forebrain that enhance processing of sensory information. We have observed that bilateral infusions of a noradrenergic $\beta$-antagonist into MS block EEG activation observed after LC activation in the anesthetized rat (C. Berridge and S. Foote, unpublished observations). However, this observation does not exclude the possibility that normal EEG activation and waking depend on the concerted/combined actions of NE within MS and other LC terminal fields. Future studies will need to address the degree to which NE actions within neocortical, hippocampal, and thalamic regions contribute to alterations in EEG and behavioral state.

LC neuronal activity fluctuates across two temporal dimensions. Stable and prolonged alterations in tonic discharge rates precede, and are maintained throughout, alterations in behavioral state (Foote et al., 1980; Aston-Jones and Bloom, 1981a). Within waking, LC neurons respond phasically to salient sensory information (Foote et al., 1980; Aston-Jones and Bloom, 1981b). Recent work in monkeys demonstrates that phasic fluctuations in vigilance are preceded by phasic changes in the activity of LC noradrenergic neurons (Aston-Jones et al., 1994). Although correlative in nature, these studies provide support for the hypothesis that phasic alterations in LC discharge rates that occur within waking are critically involved in short-term fluctuations in vigilance. Similar to previous descriptions (Foote et al., 1980; AstonJones and Bloom, 1981a), the phasic fluctuations in LC neuronal activity observed by Aston-Jones et al. (1994) were superimposed on prolonged and stable changes in tonic LC neuronal discharge rates that were associated with changes in behavioral and EEG measures of alertness.

Thus, it is posited that through the coordinated actions of LC efferents across multiple terminal fields, LC may serve at least two general functions. First, LC neurons may facilitate the induction of a behavioral state appropriate for acquisition of sensory information (e.g., waking). This action is proposed to be dependent on changes in tonic activity of LC neurons and, at least in part, involves actions of NE at $\beta$-receptors located within MS. Second, LC may facilitate state-dependent cognitive processes (e.g., vigilance), which are, at least in part, modulated by phasic fluctuations in LC neuronal activity and possibly involve actions of NE within cortical and thalamic terminal fields. Combined, these actions would serve to facilitate appropriate behavioral responding to sensory information.

\section{REFERENCES}

Adams LM, Foote SL (1988) Effects of locally infused pharmacological agents on spontaneous and sensory-evoked activity of locus coeruleus neurons. Brain Res Bull 21:395-400.

Aston-Jones G, Bloom FE (1981a) Activity of norepinephrinecontaining locus coeruleus neurons in behaving rats anticipates fluctuations in the sleep-waking cycle. J Neurosci 1:876-886.

Aston-Jones G, Bloom FE (1981b) Norepinephrine-containing locus coeruleus neurons in behaving rats exhibit pronounced responses to non-noxious environmental stimuli. J Neurosci 1:887-900.

Aston-Jones G, Rajkowski J, Kubiak P, Alexinsky T (1994) Locus coeruleus neurons in monkey are selectively activated by attended cues in a vigilance task. J Neurosci 14:4467-4480.
Bergmann BM, Winter JB, Rosenberg RS, Rechtschaffen A (1987) NREM sleep with low-voltage EEG in the rat. Sleep 10:1-11.

Berridge CW, Dunn AJ (1990) DSP-4-induced depletion of brain norepinephrine produces opposite effects on exploratory behavior 3 and 14 days after treatment. Psychopharmacology 100:504-508.

Berridge CW, Foote SL (1991) Effects of locus coeruleus activation on electroencephalographic activity in neocortex and hippocampus. J Neurosci 11:3135-3145.

Berridge CW, Foote SL (1993) Stimulation of medial septal noradrenergic $\beta$-receptors induces behavioral and forebrain EEG activation. Soc Neurosci Abstr 21:2092.

Berridge CW, Page ME, Valentino RJ, Foote SL (1993) Effects of locus coeruleus inactivation on electroencephalographic activity in neocortex and hippocampus. Neuroscience 55:381-393.

Berridge CW, Bolen SJ, Manley MS, Foote SL (1996) Modulation of forebrain electroencephalographic (EEG) activity in halothaneanesthetized rat via actions of noradrenergic $\beta$-receptors within the medial septal region. J Neurosci 0:000-000.

Buzsaki G, Bickford RG, Ponomareff G, Thal LJ, Mandel R, Gage FH (1988) Nucleus basalis and thalamic control of neocortical activity in the freely moving rat. J Neurosci 8:4007-4026.

Chang HT (1989) Noradrenergic innervation of the substantia innominata: a light and electron microscopic analysis of dopamine $\beta$-hydroxylase immunoreactive elements in the rat. Exp Neurol 104:101-112.

Cunningham JT, Nissen R, Renaud LP (1992) Norepinephrine injections in diagonal band of Broca selectively reduce the activity of vasopressin supraoptic neurons in the rat. Brain Res 610:152-155.

De Sarro GB, Ascioti C, Froio F, Libri V, Nistico G (1987) Evidence that locus coeruleus is the site where clonidine and drugs acting at $\alpha-1$ - and $\alpha$-2-adrenoceptors affect sleep and arousal mechanisms. Br J Pharmacol 90:675-685.

De Sarro GB, Bagetta G, Libri V, Nistico G (1988) Microinfusion of clonidine and yohimbine into locus coeruleus alters EEG power spectrum: effects of aging and reversal by phosphatidylserine. Br J Pharmacol 95:1278-1286.

Deutch AY, Bourdelais AJ, Zahm DS (1993) The nucleus accumbens core and shell: accumbal compartments and their functional attributes. In: The mesolimbic motor circuit and its role in neuropsychiatric disorders, pp 45-88. Boca Raton: CRC.

Diaz J, Elison G, Masouka D (1978) Stages of recovery from central norepinephrine lesions in enriched and impoverished environments: a behavioral and biochemical study. Exp Brain Res 31:117-130.

Foote SL, Aston-Jones G (1995) Pharmacology and physiology of central noradrenergic systems. In: Psychopharmacology: the fourth generation of progress (Bloom FE, Kupfer DJ, eds), pp 335-345. New York: Raven.

Foote SL, Freedman FE, Oliver AP (1975) Effects of putative neurotransmitters on neuronal activity in monkey auditory cortex. Brain Res 86:229-242.

Foote SL, Aston-Jones G, Bloom FE (1980) Impulse activity of locus coeruleus neurons in awake rats and monkeys is a function of sensory stimulation and arousal. Proc Natl Acad Sci USA 77:3033-3037.

Fink M, Irwin P (1981) CNS effects of clonidine in normal volunteers. Psychopharmacol Bull 17:16-17.

Flicker CM, Geyer A (1982) Behavior during hippocampal microinfusions. I. Norepinephrine and diversive exploration. Brain Res Rev 4:79-103.

Gaspar P, Berger B, Alvarez C, Vigny A, Henry JP (1985) Catecholaminergic innervation of the septal area in man: immunocytochemical study using TH and DBH antibodies. J Comp Neurol 241:12-33.

Groenewegen HJ, Russchen FT (1984) Organization of the efferent projections of the nucleus accumbens to pallidal, hypothalamic, an mesencephalic structures: a tracing and immunohistochemical study in the cat. J Comp Neurol 223:347-367.

Hallman H, Jonsson G (1984) Pharmacological modifications of the neurotoxic action of the noradrenaline neurotoxin DSP-4 on central noradrenaline neurons. Eur J Pharmacol 103:269-278.

Harik JL (1984) Coeruleus lesion by local 6-hydroxydopamine infusion causes marked and specific destruction of noradrenergic neurons, longterm depletion of and enhanced dopaminergic mechanisms in the ipsilateral cerebral cortex. J Neurosci 4:699-707.

Heimer L, Zahm DS, Churchill L, Kalivas PW, Wohltmann C (1991) Specificity in the projection patterns of accumbal core and shell in the rat. Neuroscience 41:89-125. 
Hobson JA, McCarley RW, Wyzinski PW (1975) Sleep cycle oscillation: reciprocal discharge by two brainstem neuronal groups. Science 189:55-58.

Hobson JA, Lydic R, Baghdoyan HA (1986) Evolving concepts of sleep cycle generation: from brain centers to neuronal populations. Behav Brain Sci 9:371-448.

Ino T, Itoh K, Kamiya H, Shigemoto R, Akiguchi I, Mizuno N (1988) Direct projections of non-pyramidal neurons of Ammon's horn to the supramamillary region in the cat. Brain Res 460:173-177.

Jouvet M (1972) The role of monoamines and acetylcholine containing neurons in the regulation of the sleep waking cycle. Ergeb Physiol Biol Chem Exp Pharmakol 64:166-307.

Lidbrink P (1974) The effects of lesions of the ascending noradrenaline pathways on sleep and waking in the rat. Brain Res 74:19-40.

McCormick DA, Pape HC (1990) Noradrenergic and serotonergic modulation of a hyperpolarization-activated cation current in thalamic relay neurons. J Physiol (Lond) 431:319-342.

Meibach RC, Siegel A (1977) Efferent connections of the septal area in the rat: an analysis utilizing retrograde and anterograde transport methods. Brain Res 119:1-20.

Metherate R, Cox CL, Ashe JH (1992) Cellular bases of neocortical activation: modulation of neural oscillations by the nucleus basalis and endogenous acetylcholine. J Neurosci 12:4701-4711.

MilnerTA (1991) Ultrastructural localization of tyrosine hydroxylase immunoreactivity in the rat diagonal band of Broca. J Neurosci Res 30:498-511.

Mogenson GJ, Swanson LW, Wu M (1983) Neural projections from nucleus accumbens to globus pallidus, substantia innominata, and lateral preoptic-lateral hypothalamic area: an anatomical and electrophysiological investigation in the rat. J Neurosci 3:189-202.

Page ME, Berridge CW, Foote SL, Valentino RJ (1993) Corticotropinreleasing factor in the locus coeruleus mediates EEG activation associated with hypotensive stress. Neurosci Lett 164:81-84.

Pape HC, McCormick DA (1989) Noradrenaline and serotonin selectively modulate thalamic burst firing by enhancing a hyperpolarizationactivated cation current. Nature 340:715-718.

Saper CB (1984) Organization of cerebral cortical afferent systems in the rat. II. Magnocellular basal nucleus. J Comp Neurol 222:313-342.

Segal DS (1975) Behavioral characterization of D- and L-amphetamine: neurochemical implications. Science 190:475-477.

Segal DS, Mandell AJ (1970) Behavioral activation of rats during intraventricular infusion of norepinephrine. Proc Natl Acad Sci USA 66:289-293.

Segal IS, Vickery RG, Walton BS, Dose VA, Maze M (1988) Dexmedetomidine diminishes halothane anesthetic requirements in rats through a postsynaptic $\alpha 2$ adrenergic receptor. Anesthesiology 69:818-823.
Segal M (1976) Brain stem afferents to the rat medial septum. J Physiol (Lond) 261:617-631.

Steriade M, McCarley RW (1990) Brainstem control of wakefulness and sleep. New York: Plenum.

Steriade M, Datta S, Pare D, Oakson G, Dossi RC (1990) Neuronal activities in brain-stem cholinergic nuclei related to tonic activation processes in thalamocortical systems. J Neurosci 10:2541-2559.

Stewart DJ, Macfabe DF, Leung LWS (1985) Topographical projection of cholinergic neurons in the basal forebrain to the cingulate cortex in the rat. Brain Res 358:404-407.

Swanson LW, Cowan WM (1977) An autoradiographic study of the organization of the efferent connections of the hippocampal formation in the rat. J Comp Neurol 172:49-84.

Swanson LW, Cowan WM (1979) The connections of the septal region in the rat. J Comp Neurol 186:621-656.

Timo-Iaria C, Negrao N, Schmidek WR, Hoshino K, Lobato de Menezes CE, Da Rocha TL (1970) Phases and states of sleep in the rat. Physiol Behav 5:1057-1062.

U'Prichard DC, Reisine TD, Mason ST, Fibiger HC, Yamamura HI (1980) Modulation of rat brain $\alpha$ - and $\beta$-adrenergic receptor populations by lesion of the dorsal noradrenergic bundle. Brain Res 187:143-154.

Vanderwolf CH (1988) Cerebral activity and behavior: control by central cholinergic and serotonergic systems. Int Rev Neurobiol 30:225-341.

Vanderwolf CH, Robinson TE (1981) Reticulo-cortical activity and behavior: A critique of the arousal theory and a new synthesis. Behav Brain Sci 4:459-514.

Vertes RP (1988) Brainstem afferents to the basal forebrain in the rat. Neuroscience 24:907-935.

Walaas I, Fonnum F (1980) Biochemical evidence for glutamate as a transmitter in hippocampal efferents to the basal forebrain and hypothalamus in the rat. Neuroscience 5:1691-1698.

Woodward DJ, Moises HC, Waterhouse BD, Hoffer BJ, Freedman R (1979) Modulatory actions of morepinephrine in the central nervous system. Fed Proc 38:2109-2116.

Zaborsky L (1989) Afferent connections of the forebrain cholinergic projection neurons, with special reference to monaminergic and peptidergic fibers. In: Central cholinergic synaptic transmission (Frotscher M, Misgel U, eds), pp 12-32. Basel: Birkhauser.

Zaborszky L, Alheid GF, Beinfeld MC, Eiden LE, Heimer L, Palkovits M (1985) Cholecystokinin innervation of the ventral striatum: a morphological and radioimmunological study. Neuroscience 14:427-453.

Zaborszky L, Cullinan WE, Braun A (1991) Afferent to basal forebrain cholinergic projection neurons: an update. In: The basal forebrain (Napier TC, ed), pp 43-100. New York: Plenum. 